\title{
ECLECTICISMO ATMOSFÉRICO \\ POÉTICAS DEL AMBIENTE EN LA ARQUITECTURA \\ CONTEMPORÁNEA
}

\author{
Eduardo Prieto \\ Doctor Arquitecto Profesor ETSAM Madrid. Redactor Arquitectura Viva \\ ASTRAGALO, 20 (2015) \\ Attribution-NonCommercial-ShareAlike - CC BY-NC-SA \\ Artículo, ISSN 2469-0503 \\ https://dx.doi.org/10.12795/astragalo.2015.i20.09
}

\begin{abstract}
Considerando las categorías que delimitan la nueva estética de las atmósferas en la arquitectura, alguien podría deducir que existe una escuela ambientalista como tal o que, al menos, las propuestas que hoy se concibe y, en menor medida, se construyen con tales principios comparten un aire de familia. Nada más lejos, sin embargo, de la realidad. En rigor, amplia denotación del concepto de "atmósfera" haya espacio para una pluralidad de lenguajes, aunque éstos no compartan acaso más que una aspiración muy vaga y general a la ligereza o a la inmaterialidad, una poética que suele describirse además en términos más o menos termodinámicos. Por todo ello, parece un tanto pretencioso acotar unívocamente una estética de las atmósferas. Sin duda, sería más justo describir las exploraciones diversas del fenómeno ambiental como poéticas específicas, por no decir que subjetivas, abriendo así hueco a la posibilidad de un eclecticismo atmosférico.
\end{abstract}

No resulta difícil identificar la primera de estas poéticas. Se remonta a las escenografías barrocas y como ellas, se sostiene en la producción de efectos con materiales etéreos como la luz y el color. Este Barroco redivivo (presente por ejemplo, en tantas obras de Jean Nouvel) exacerba y a la vez matiza las experiencias modernas sobre la transparencia y el reflejo, aparte de hacerse eco de las investigaciones fenomenológicas sobre las trampas y las sorpresas que acechan a nuestra falible percepción al enfrentarse con el espacio habitado. En los reflejos y la desmaterialización depende precisamente el efecto de la Fundación Cartier parisina situada en una parcela convencional del ensanche haussmanniano, que Nouvel fragmenta en planos de vidrio entreverados de vegetación y que producen una impresión variable de opacidad o transparencia conforme cambian las condiciones lumínicas a lo largo del año y en función 
de los meteoros. El resultado es la desmaterialización aparente, el fundido de los límites del edificio, que a veces se confunde con los árboles y a veces parece quedar engullido por la trama urbana. El arquitecto francés sigue una estrategia semejante en buena parte de los palacios de congresos, auditorios y óperas que ha construido a lo largo de su carrera, siguiendo la tradición francesa de las grandes dotaciones culturales. Por su parte, en el Palacio de Congresos de Tours Nouvel se muestra un digno heredero de Garnier, pues al igual que él funde una planta rigurosamente académica y un exterior de volumetría enfática con un interior que se muestra a los ojos como un despliegue de efectos casi sinestésicos, donde los reflejos desdibujan el contorno construido y donde los juegos de color activan los espacios comunes de un modo que recuerda las grandes pantallas de neón características de Nueva York o Tokio. El hecho de que Nouvel haya ido perdiendo fuelle creativo en las últimas décadas no impide considerar la brillantez barroca de sus primeras edificios, manifiesta aún en obras como la cúpula atmosférica del Museo del Louvre de Abu Dabi, un megalómano sombrajo calado de motivos islámicos que recuerda un tanto a algunas obras de sus discípulos, como el reciente Museo de las Culturas Mediterráneas en Marsella, de Rudy Ricciotti, cuya característica celosía organicista cobija una atmósfera interior de profundos claroscuros.

El trato efectista y fenomenológico de los materiales y la luz también es la clave del juego ilusionista que define el trabajo del equipo RCR. Se trata en este caso de una versión extremada en su minimalismo formal, pero que descree de cualquier tipo de connotación es- pectacular o barroca para profesar una estética despojada, de tintes orientales, acaso zen. Así lo manifiestan los pabellones de relajación de su Hotel y restaurante Les Cols, en Olot, construidos con inasibles membranas de vidrio que, con cierta tiranía, se extienden por paredes, suelo y techo, resguardadas del exterior gracias a una serie de velos silenciosos y exquisitos. La atmósfera cambiante creada por tal materialidad concentrada sugiere un mundo flotante de sosiego y una sofisticada relación con la naturaleza, que parecen poner entre paréntesis el trajín fluido e inasible del mundo globalizado y su banalidad icónica.

\section{DE LA CABAÑA PRIMITIVA A LA BURBUJA DIGITAL}

Es precisamente este trajín fluctuante de nuestro mundo líquido el que inspira a otro investigador contemporáneo de las atmósferas: Toyo Ito. La estética de lo efímero está ya presente en una de sus primeras obras, la Torre de los Vientos (1987) de Yokohama, concebida como una suerte de "diseño del aire". Fue una instalación efímera y fluctuante, consistente en una etérea piel de celosía metálica enrollada en torno a un depósito de agua a modo de pantalla de proyección. Heredera en cierto sentido de los artefactos cibernéticos de Nicholas Schöffer, la Torre intentaba, en el fondo, llevar a término una parte del programa futurista, entrando en resonancia tanto con la ciudad como con la naturaleza, para "volver visible el ruido existente en el aire de la ciudad". Su apariencia estática y minimalista se transformaba al llegar la noche. Conectado a una red de anemómetros y detectores de ruido, un software permitía responder al flujo natural de los vientos y del 
ruido producido por tráfago urbano con un flujo artificial de luces declinadas en diferentes intensidades y colores. El resultado era una atmósfera parlante de energía, transitoria y desmaterializada, que impregnaba su entorno con su cinetismo espontáneo.

Toyo Ito considera que la "arquitectura del viento", valga decir atmosférica, es acaso la única posible en un mundo sometido a flujos inasibles de información y en el que presuntamente, la realidad ha perdido espesor y tiende incluso a ser sustituida por la virtualidad informática. Hoy sabemos que en realidad, los procesos de evanescencia que impone la globalización son fundamentalmente financieros y que las presuntas identidades líquidas que aquella genera se resuelven más bien en la banalidad de los seudónimos de los chats o de Twitter y muchas veces no tienen más fin que una huera multiplicación de la capacidad de consumir a través de las herramientas digitales. Sin embargo, en la década de 1990 — que es cuando Toyo Ito publica sus escritos más influyentes y construye sus obras más emblemáticas - lo digital aún tenía un sentido promisorio y a muchos les parecía que podía cambiar la arquitectura. Como ocurre siempre, las propuestas promisorias, vulgo utopías, suelen sostenerse en mitos primigenios o inventados. Tal es el sentido, por supuesto, del bon sauvage de los ilustrados — símbolo de la naturaleza humana universal- y en el ámbito de la arquitectura, de las llamadas "cabañas elementales", como la propuesta por Laugier por las mismas fechas en que Rousseau escribía su Discurso sobre la desigualdad entre los hombres.

Toyo Ito no es menos que los anteriores y propone fundar la nueva mitología arquitectónica de la sociedad líquida con una versión puesta al día de la cabaña primitiva. "Para nosotros, habitantes de la ciudad", escribe Ito en 1988, “como nómadas que sólo podemos reconocer la 'casa' uniendo varias de sus funciones que están esparcidas en medio de la ciudad como si fueran pedazos de un cristal roto resulta pertinente que volvamos a pensar, una vez más, en la cabaña primitiva." Esta cabaña sin embargo, ya no está en el bosque, sino en la selva icónica de las metrópolis de la información, y no está habitada por cuerpos humanos sino por 'androides' de sensibilidad más sintética que natural. Lo que perciben estos ya no es el "torrente de la montaña", sino ese otro torrente en el que se encauzan tanto "el ir y venir de los automóviles en las autopistas como el flujo de las corrientes magnéticas".

Así, en un mundo donde ya no hay bases estables donde apoyarse, y donde los flujos son sólo asideros engañosos y efímeros, la "cabaña primitiva en la que tenemos que refugiarnos no tiene una composición clara con columnas y vigas como la describía Laugier, sino (...) que es un abrigo cubierto por un velo suave e invisible". Como para los cuerpos androides - los nuestros, presuntamente- no tiene sentido encerrarse entre cuatro pesadas paredes para preservar una verdad existencial que no les preocupa o una potencia imaginativa que ya no tienen (a la manera de los fenomenólogos), lo pertinente es abrirse a los flujos, romper los muros para ponerse a favor del sentido de la corriente, encaramándose a la cresta de la ola para que no nos derribe. Desde este punto de vista, como recuerda Christine Buci-Glucksmann, lo efímero no tiene un sentido melancólico - la fugacidad de la vida moderna recortada sobre el fondo de la eternidad, como había escrito Baudelaire - sino uno positivo, que consiste 
en aprovechar el momento de acuerdo a una versión líquida y antimetafísica del beatus ille. De hecho, etimológicamente, lo efímero alude a la conquista del "momento favorable", ya que cada día, cada oportunidad es diferente y entraña por tanto nuevas posibilidades.

$\mathrm{El}$ arte atmosférico es pues, un arte del momento. Por ello la arquitectura debe abrirse a su entorno para desplegar en él sus antenas, para "buscar la ocasión", que dirían los antiguos, despojándose de los gruesos muros de antaño. "¿No es necesario que quitemos la pared que separa el interior del exterior?", se pregunta retóricamente Ito, y continúa: "Hace falta producir una corriente de aire entre el espacio real y el ficticio. Este último va creciendo desde el interior, delimitado sólo por una fina capa, y no se debe intentar someterlo a un orden arquitectónico, sino que hay que dejarlo flotar en medio de la realidad." Este programa pragmático y promisorio a la vez explica la estética flotante y borrosa de Toyo Ito, denominada por él como "de los límites difusos", y que consiste en construcciones de materialidad mínima y de máxima apertura al exterior que buscan cumplir el ideal de una arquitectura "suave y flexible, como una película delgada que envuelve el cuerpo humano y lo cubre en su totalidad".

En la arquitectura de Toyo Ito (que, como la de tantos otros, ha sufrido una decadente deriva formalista e icónica) la obra más cercana a este ideal atmosférico es la Mediateca de Sendai, cuya envolvente resulta desmaterializada sin dejar de ser una inmensa pantalla de información y cuyos "árboles" metálicos encauzan y expresan formalmente los flujos que se producen en el interior del edificio. Son recursos que dan cuenta, de un modo más bien analógico, del ideario de su autor, en cuanto son una materialización de la "película delgada", de la "filmina abierta a un paisaje de signos" que, como quería Klee o los futuristas, permita volver "visible el fluir de las cosas invisibles como el aire". Y todo ello "siguiendo la corriente incesante de las informaciones y la naturaleza, pero organizándolos con un mínimo formalismo".

Trufadas sociología de andar por casa, las propuestas de Toyo Ito no han encontrado una adecuada expresión en sus propias obras, sino en las de algunos de sus discípulos. SANAA ha asumido con literalidad el reto de organizar los flujos de la vida que atraviesan la arquitectura, en trabajos que sintetizan de manera inesperada el pintoresquismo atmosférico con el minimalismo formalista. En ellos se cumple, más que en cualquier otro arquitecto del momento, el dictum de la estética atmosférica según el cual la riqueza de los ambientes interiores resulta proporcional al esquematismo de las trazas. Compuestas a partir de combinaciones aparentemente inocentes de rectángulos y círculos, las trazas de las obras de SANAA tienen en efecto, el rigor y la esencialidad casi infantil de un diagrama construido y conviven con una materialidad no menos lacónica que sin embargo, resulta ser la desconcertante condición para el fabuloso juego atmosférico desplegado en los interiores de sus edificios, un juego cuyosmateriales son el espacio, la luz, el aire, el color blanco y los meteoros naturales con que estos, espontáneamente, entran en resonancia. Como escribe Luis Fernández-Galiano, las obras de SANAA "procuran desprenderse del grosor, prescindir de la inercia, liberarse de la densidad" de acuerdo a un proceso que produce "objetos de apariencia inmaterial, metafísicos en tanto trascienden las convenciones cotidianas del mundo sensorial, y oníricos en cuanto alojados 
en la frontera imprecisa que separa el sueño y la vigilia”. No hay en ellos nada de presuntuoso desprecio de las formas tradicionales, sino un esfuerzo constante de selección y depuración de éstas, que desde el programa conduce a la composición y desde la composición a la construcción, hasta llegar a la atmósfera final. Por el camino, los cerramientos se diluyen, la estructura se atomiza hasta volverse casi imperceptible y el volumen se desmaterializa, como ocurre en algunas de sus obras más señeras, como el Museo de Kanazawa o el Pabellón de Vidrio del Museo de Toledo (Ohio), que evoca y actualiza otros pabellones hermanos como el de Mies en Barcelona o la Glashaus de Bruno Taut.

En los edificios de SANAA, por tanto, el diagrama de flujos se condensa en una serie de figuras elementales cuya percepción en la experiencia real del edificio no tiene, sin embargo, nada de esquemática, pues se disuelve en un flujo y reflujo imprevisible de reflejos, transparencias y tornasoles en los que juegan un papel importante los meteoros naturales. La evanescencia material y el efecto de sorpresa que de ella emana procede en último término de la actividad imprevisible de la naturaleza que, como escribe Iñaki Ábalos, permite pasar “de la transparencia total a la opacidad impenetrable y alucinada como resultado de la multiplicación laberíntica de reflejos activados y desactivados simplemente con el paso de una nubecilla, con un soplo de aire". Los obras de SANAA parecen sugerir la idea de que no puede haber una atmósfera arquitectónica sin una natural.

\section{LA ESTÉTICA DE LO EVANESCENTE}

El proceso de disolución de la materia y de fusión de la atmósfera arquitectónica con la naturaleza se acentúa hasta un minimalismo paroxístico en la obra de uno de los discípulos de Sejima, Junya Ishigami, cuyos edificios (que siempre desbordan la disciplina en una fuga personal hacia el arte) son como prolongaciones del medio ambiente o atmósferas puras, sostenidos apenas por pilares o tensores imperceptibles, y acotados con levísimas membranas de vidrio que en realidad, no pretenden separarse de la naturaleza, ni ponerle, como suele decirse, puertas al campo.

Los casos más extremos de desmaterialización, exitosos en el sentido de que parecen demostrar que la arquitectura puede molecularizarse o convertirse literalmente en energía, no tienen que ver con la corriente minimalista japonesa, sino que proceden del mundo de las instalaciones artísticas. Entre ellos destaca el Blur Building que Diller + Scofidio presentaron en 2002 para la exposición suiza de Yverdonsles-Bains. Se trataba de una gran nube artificial producida por una red de humectadores cosidos a una estructura tensada que desaparecía completamente en la densidad vaporosa. Cuando el artefacto estaba en marcha no podía hablarse de que tuviera una forma sino en un sentido precario y transitorio, pues la nube, sometida a las potencias de la luz y el viento, e inasible por su propia condición vaporosa, cambiaba continuamente de aspecto, dando así cuenta de un equilibrio entre lo natural y lo artificial que en algunas ocasiones se decantaba del lado del artificio mientras que las más de las veces lo hacía del de la naturaleza. Contemplada desde fuera, la nube presentaba la condición de un icono visual, daba forma a lo que en sí mismo es informe; de ahí que, una vez desmontado el pabellón, la crítica incidiese sobre todo en la imagen vaporosa pero estática sugerida por las 
fotografías, olvidando el sentido fenomenológico con que la concibieron sus autores.

De hecho, más que en un edificio, el Blur Building consistía en una experiencia de transgresión perceptiva afín a las concebidas por James Turrell o la que sólo un año antes había presentado Olafur Eliasson en la Kunsthaus Bregenz. Al entrar en la instalación, el visitante dejaba de percibirla como una forma reconocible, para experimentarla de una manera inquietante. La nube devenía niebla, un éter denso que envolvía su cuerpo y el de aquéllos que, como él, se habían pertrechado de un chubasquero que los igualaba a todos. La experiencia servía para poner en crisis todos los presupuestos perceptivos: al abismarse en un espacio anublado y desorientador, el visitante perdía sus referencias visuales y tomaba conciencia de su propio cuerpo fundido con la atmósfera. Con ello se materializaba la hipótesis fenomenológica de Bollnow o Bachelard, cuando al describir la experiencia perceptiva de la niebla o la oscuridad sugerían la existencia de un sentimiento de espacialidad originaria, prerreflexiva y ciega. El Blur Building contradecía así la vieja tradición pedagógica y a la vez ilusionista de los pabellones del siglo XIX, pues en realidad el edificio no enseñaba nada; más bien "borraba información". Por el contrario, los edificios para las ferias mundiales y las exposiciones universales alimentaban "el apetito insaciable del público por despliegues cada vez más grandes de virtuosismo tecnológico" de tal manera que, según Diller + Scofidio, aquella "sobre-estimulación visual provocaba un efecto des-sensibilizador: cuantos más estímulos reciben nuestros ojos, menos vemos". En el Blur Building por tanto, "lo "borroso es una respuesta al ruido visual, desafía nuestra dependencia de la vista como sentido dominante" pues, a fin de cuentas, "lo que muestra este pabellón expositivo es la propia visión".

Las utopías de desmaterialización extrema actualizan de este modo, los viejos debates fenomenológicos sobre la jerarquía de los sentidos, incorporando asimismo las experiencias de desorientación perceptiva pergeñadas por artistas como James Turrell u Olafur Eliasson. Las instalaciones y proyectos del arquitecto suizo Philippe Rahm parten de las mismas premisas estéticas y epistemológicas. Si por un lado se conciben como "construcciones de aire", por el otro suscriben la desconfianza hacia lo visual que desde Diderot hasta Pallasmaa, pasando por Merleau-Ponty, dio forma a parte de la cultura moderna. Rahm juzga que el "campo de lo visible", hasta ahora "saturado de símbolos, de moral, de relatos y de intereses particulares" es incapaz de sostener el "nuevo humanismo" de las sociedades globales, que son abiertas, líquidas y flotantes. Contagiada de la ineptitud de las tradiciones ocularcentristas, la arquitectura también debe mutar, "deslizándose hacia lo invisible" y dotándose de medios ligeros para producir "paisajes libres, nuevas geografías y otras meteorologías". Así, en lugar de espacios cerrados con argumentos dados de una vez, la arquitectura debe crear atmósferas abiertas continuamente a la interpretación y a la creatividad, en las cuales "los límites se evaporen y las estructuras se disipen".

Pese a que este discurso comparta su tono general con las propuestas de los futuristas y los situacionistas, así como con la jerga sobre lo visible y lo invisible esbozada por el propio Merleau-Ponty, el paradigma estético que Rahm propone para llevarlo a término es 
estrictamente contemporáneo: combina la imaginería etérea de las instalaciones de Turrell y Eliasson con las tesis paramétricas sobre los flujos termodinámicos. La premisa de esta estética de lo invisible es la existencia de gradientes. Rahm recurre a Schrödinger y Prigogine para recordarnos que el paradigma contemporáneo sobre la vida ya no se concibe como un equilibrio sino como una precaria organización mantenida merced al gasto continuado de energía, un orden entrópico, como el de las estructuras disipativas. Todo ello tiene su equivalencia arquitectónica. Mientras que el equilibrio se asociaría con la simetría clásica de las formas, el desequilibrio lo haría con las asimetrías presentes en los flujos energéticos, de ahí que la noción de lo bello — si es que puede mantenerse aún tal cosa- adquiera un sentido termodinámico. $\mathrm{Pa}$ ralelamente, Rahm propone superar las nuevas versiones de la simetría y la homogeneidad que en relación con el clima, ha producido la generalización del aire acondicionado, y cuya consecuencia es la "normalización y banalización" de los ambientes interiores, y el subsiguiente "empobrecimiento de la diversidad climática".

La apuesta de Rahm por tanto, es despojar a la arquitectura de cualquier presuntuosa estabilidad y de cualquier sospechosa simetría, y asimismo despojarnos nosotros mismos del prejuicio de que habitamos un espacio vacío, para explorar configuraciones que den cuenta de la atmósfera real que nos rodea, una "atmósfera electromagnética, química, sensorial, en la cual estamos sumergidos, y a la cual contribuimos con nuestra respiración, transpiración, el calor emitido por nuestro cuerpo y nuestra actividad física y hormonal". Desde este punto de vista, proyectar significa distribuir los flujos de energía variables que atraviesan esa atmósfera, dotándolos de un sentido acorde con las condiciones fisiológicas y meteorológicas gracias a un trabajo que parte de gradientes deshumanizados y llega a gradientes antropológicos.

No otra cosa sino un gradiente de energía domesticado es la instalación Digestible Gulf Stream que Rahm presentó en la Bienal de Venecia de 2008. Consistía en un espacio acotado por barreras invisibles, un éter que suponemos controlado climáticamente al comprobar que los cuerpos que allí habitan están desnudos. El confort lo proporcionan las dos plataformas de acero que rigidizan la estructura y sirven de apoyo ocasional a dichos cuerpos, plataformas que están calentadas a temperaturas diferentes - la inferior a $28^{\circ} \mathrm{C}$; la superior a $12-$ y situadas de manera que se genere una corriente de convección semejante a la que da nombre a la instalación, la corriente del Golfo. Es pues, la estratificación del aire en función de su temperatura la que organiza los espacios habitados; no hay más particiones que las invisibles que conducen a través del gradiente, de un estrato térmico a otro.

El resultado es una suerte de nuevo funcionalismo termodinámico por el cual la geometría de los ambientes se sigue de los condicionantes climáticos, y no al revés. Como escribe Rahm, a modo de manifiesto, la función y la forma siguen al clima: "Trabajamos en una inversión de los métodos de proyecto tradicionales con el fin de permitir una nueva organización del espacio en la que la función y la forma podría surgir de manera espontánea a partir del clima. Lo que nos importa es obrar con la materia del propio espacio, la densidad del aire y la intensidad de la luz, para ofrecer una arquitectura que se asemejaría a una geo- 
grafía: una meteorología abierta y cambiante, con climas y calidades atmosféricas diferentes, que se habitaría en función de la actividad, la hora del día, la estación, nuestras necesidades y nuestros deseos."

\section{ENTRE EL ESTETICISMO Y EL HAPTICISMO}

Las obras de Nouvel, Ito, SANAA, Ishigami, Diller + Scofidio o Rahm ponen de manifiesto que, en realidad, no hay tal cosa como una estética de la energía. Si Nouvel actualiza la vieja tradición del ilusionismo barroco, con sus trampantojos y reflejos, Ito indaga en las características de nuestras sociedades mudables y efímeras para dar cuenta de ellas mediante una arquitectura que acaba siendo formalista, por más que se pretenda desmaterializada y cibernética. Sejima se sirve del discurso de su maestro pero transforma la evanescencia teórica de éste en una evanescencia construida y veraz, combinada con un lacónico minimalismo geométrico sin que por ello se resienta su asombroso poder de entrar en resonancia con la naturaleza. Partiendo de estas premisas, Ishigami recae ya en el esteticismo, poniendo el fulcro de su sensibilidad más cerca del arte. La misma posición descentrada adopta la balanza de Diller + Scofidio y Philippe Rahm, cuyas obras tienen el carácter de instalaciones experimentales: el vapor en unos, y el calor en el otro, se convierten más en argumentos estéticos que propiamente en herramientas para transformar la realidad.

El fracaso parcial del ala esteticista de la arquitectura de la energía es compartido en parte por el ala existencial. Salvo en el caso de Zumthor - cuya adopción del concepto de atmósfera es realmente creativo-, las arqui- tecturas fenomenológicas palidecen respecto de los ambiciosos principios con que se conciben: materialmente no logran ir más allá de las soluciones establecidas por el Movimiento Moderno; ideológicamente, dependen de una ingenuidad aprendida por la cual los valores abstractos del espacio y el ocularcentrismo, desdeñados ahora en tanto alienaciones provocadas por la globalización, se sustituyen por las presuntas verdades hápticas del cuerpo en su relación prerreflexiva con el entorno, sin necesidad aparente de mediaciones sociales o políticas.

Pero la estética de las atmósferas desborda el esteticismo de la evanescencia y el autismo de la hapticidad. De hecho no deja de ser sorprendente que la semilla de la ligereza y la transitoriedad de la arquitectura y de la intensificación de los poderes del cuerpo que suele asociarse a ella, haya encontrado un campo abonado y más exitoso en otro tipo de obras, en general menospreciadas: las construcciones que con la llegada del siglo XIX se han venido erigiendo con propósitos lúdicos y sinestésicos, desde los panoramas de Barker hasta los polytopes de Xenakis, pasando por los numerosos pabellones electroacústicos de las décadas de 1950 y 1960 y también por las absurdas lucubraciones de los grupos situacionistas y tecnopop. Acaso sin pretenderlo, las construcciones festivas fueron capaces de configurar atmósferas complejas y multidimensionales; su displicencia académica resultó un campo abonado para la introducción de novedades tipológicas, técnicas y filosóficas. La conclusión, que no deja de ser paradójica, es que desde el punto de vista atmosférico, la tantas veces denostada arquitectura festiva levantada por agentes ajenos al canon moderno y en buena medida olvidada por 
la historiografía (la de las ferias de muestras y los pabellones electroacústico) ha sido a la postre la más innovadora y coherente al llevar a término, involuntariamente, el programa de inmaterialidad y fugacidad concebido hace un siglo por los futuristas italianos, con su idea de "utilizar la energía para construir el espacio".

Así y todo, a pesar de los muchos fracasos que han resultado del intento de llevarlo a la práctica, el concepto de atmósfera parece ser el único capaz de dar cuenta de las dimensiones estéticas de la energía. Lo es por su carácter acrisolador, en principio apto para fundir crea- tivamente los mundos diversos de la espacialidad, la materia y el cuerpo, y también por su versatilidad, pues resulta tan cómodo para denotar con amplitud - la belleza, la función, el clima, la energía - como para connotar cualidades estéticas muy concretas de la arquitectura contemporánea, como la desmaterialización, la evanescencia o la transitoriedad. ¿Puede haber al cabo mejor herramienta para una sociedad compuesta por presuntuosos discípulos de las nubes, y para una época en la que, como sentenció Marx, "todo lo sólido se disuelve en el aire"? 


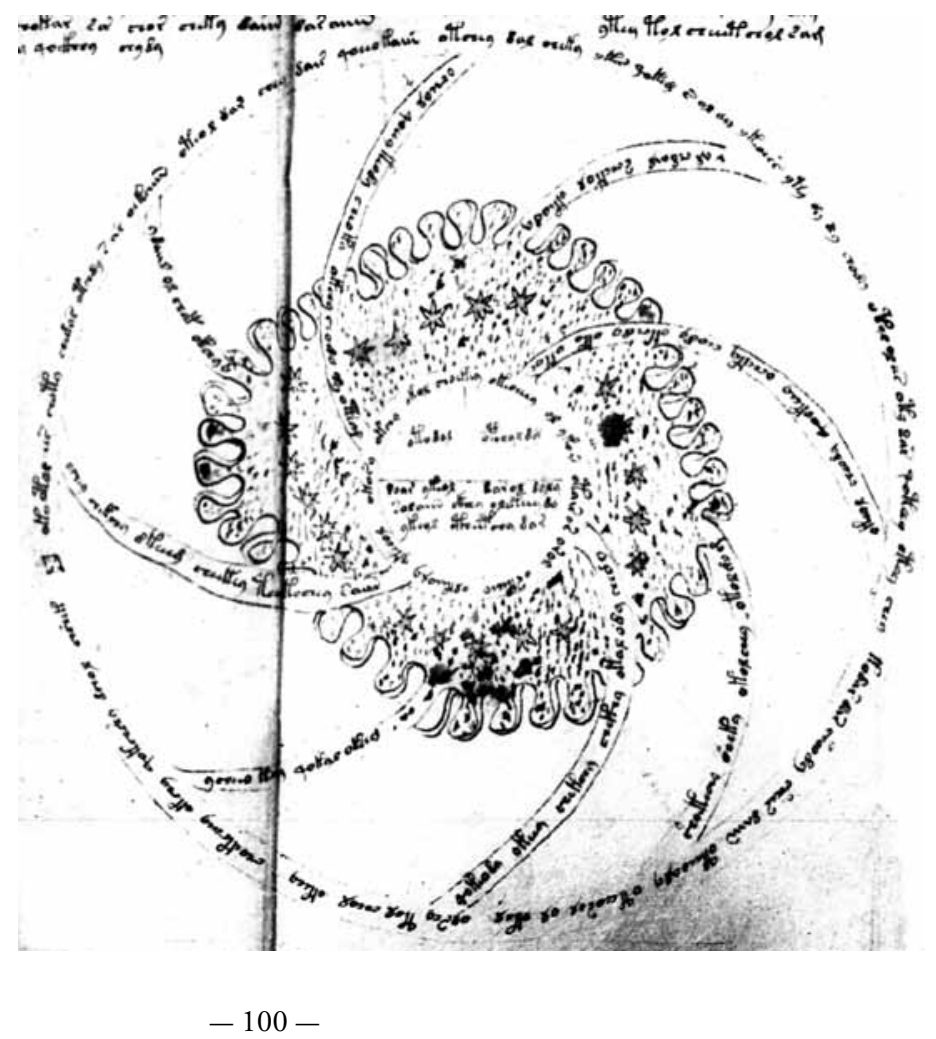

